\title{
Optimization of Losses in Permanent Magnet Synchronous Motors for Electric Vehicle Application
}

\author{
Ana Isabel León-Sánchez, Enrique Romero-Cadaval, \\ María Isabel Milanés-Montero, and Javier Gallardo-Lozano \\ Research, Development and Innovation group Power Electrical \& Electronic Systems \\ $P E \& E S$, Escuela de Ingenierías Industriales, Universidad de Extremadura, \\ Avda. de Elvas s/n, 06006 Badajoz, Spain \\ \{aleon@peandes, eromero@, milanes@, jagallardo@peandes $\}$ unex.es
}

\begin{abstract}
The aim of this paper is to analyze the influence of some parameters related with the permanent magnet motor control, which are being considered as an attractive alternative for electrical vehicle application where it is important to minimize the losses to increase the vehicle autonomy. In this paper, the attention is focused on the selection of the speed controller parameters and its impact both in mechanical losses as in the corresponding torque-speed trajectories. Moreover, the dependency of the switching frequency over the total losses in the motor-converter device is shown. The analysis determines the optimum value for the switching frequency and the results are compared with commercial servos.
\end{abstract}

Keywords: Electrical Vehicle, Permanent Magnet Synchronous Motor, Optimized losses.

\section{Introduction}

The growing interest in electric vehicles comes from the early 1990's, driven by rising fuel prices, high economic dependence between nations and strong climate impact due to the several pollutant emissions from traditional transport.

Currently, the vehicles are being developed with propulsion by energy of easy distribution and from different sources, such as electric power, not forgetting its easy availability in urban areas. Other advantage of using electric motors is the reduction of noise pollution. The proliferation of renewable energy for electricity generation helps the development of transports with electric motors.

With the increase in the use of AC motors compared with the DC motors, due to its lower cost and maintenance [1], and the mechanical benefits that they offer, new techniques have been developed for analysis. The Permanent Magnet Synchronous Motor, PMSM, does not require an external power source for excitation and exhibit high efficiency ratios compares with induction motors that have high losses in the short-circuit rotor. The application of digital control since current, torque and flux of these motors, leads the need of a compact and reliable model. These models must incorporate the essential elements of electromagnetic and mechanical behavior, for both the transient and the steady-state. The new analysis techniques of control motors places the PMSM as the motor selected for use in high performance electric vehicles achieved through the high ratio of torque-loading and adequate dynamic capacity [2]. 


\section{Contribution to Sustainability}

The use of electrical vehicles, at least in an urban environment, will contribute to the sustainability of the transport systems, decreasing the dependence of fossil fuels, decreasing also the emission of $\mathrm{CO} 2$. Also, the energy used for this kind of vehicles could be produced by renewable energy generation systems.

A key factor for electrical vehicles use promoting is their autonomy. In this paper, the influence of the coefficients used for the PI speed controllers on the overall motor response is important for minimizing the losses in vehicle applications, and so to increase vehicle autonomy, is studied.

\section{PMSM Model}

The behavior of a PMSM could be modeled by equations [3]:

$$
\begin{gathered}
u_{s q}=R_{s} i_{s q}+\omega_{e} \phi_{s d}+\frac{d\left(L_{s q} i_{s q}\right)}{d t}, \\
u_{s d}=R_{s} i_{s d}-\omega_{e} \phi_{s q}+\frac{d\left(L_{s d} i_{s d}+\phi_{f}\right)}{d t}, \\
t_{e}=\frac{3}{2} p\left(\left(L_{s d}-L_{s q}\right) i_{s d} i_{s q}+\phi_{f} i_{s q}\right), \\
\omega_{m}=\frac{\omega_{e}}{p} \\
t_{e}-t_{L}=\omega_{m} F_{r}+J \frac{d \omega_{m}}{d t} .
\end{gathered}
$$

These equations could be easily modeled in a simulation environment as, for example, MATLAB/SIMULINK. In this work, a MA-55 INFRANOR MAVILOR PMSM has been used for the simulation tests with the parameters ${ }^{1}$ shown in Table 1.

Table 1. Variables and parameters used for modeling the PMSM

\begin{tabular}{lllcl}
\hline Symbol & Nomenclature & Unit & Values & General View \\
\hline$u_{s q} ; u_{s d}$ & d-q Voltage components & $\mathrm{V}$ & - & \\
$i_{s d} ; i_{s q}$ & d-q Stator current components & $\mathrm{A}$ & - \\
$\omega_{e}$ & Motor electrical speed & r.p.s. & - & \\
$\phi_{f}$ & Magnetic flux linkage & $\mathrm{V} \mathrm{s} / \mathrm{rad}$ & - \\
$t_{e}$ & Electromagnetic torque & $\mathrm{N} \mathrm{m}$ & - \\
$\omega_{m}$ & Rotor speed & r.p.s. & - \\
$t_{L}$ & Load torque & $\mathrm{N} \mathrm{m}$ & - \\
\hline$R_{s}$ & Stator resistance & $\Omega$ & 0.7 \\
$L_{s d}$ & d-axis inductance & $\mathrm{H}$ & $1.871 \cdot 10^{-3}$ \\
$L_{s q}$ & q-axis inductance & $\mathrm{H}$ & $1.616 \cdot 10^{-3}$ \\
$p$ & Pole pairs & $\mathrm{Number}$ & 4 \\
$J$ & Moment of inertia & $\mathrm{kg} \mathrm{m}$ & $3.6 \cdot 10^{-3}$ & \\
$F_{r}$ & Viscous friction coefficient & $\mathrm{N} \cdot \mathrm{m} \cdot \mathrm{s} / \mathrm{rad}$ & $2.25 \cdot 10^{-3}$ & \\
\hline
\end{tabular}

${ }^{1} R_{s}, L_{s d}, L_{s q}, p, J$ and $F_{r}$ 


\section{PMSM Control}

The open loop control of a synchronous motor with variable frequency can develop a satisfactory variable speed when the motor works with stable values of the torque, without many requirements on speed. When the drive specifications require fast dynamic response and high accuracy in speed or torque control, the open loop control does not offer this possibility. That is why it is necessary to operate the motor in closed loop, where the operation dynamic drive system plays a fundamental role like an indicator of the system which takes part [4]. Control strategies can be classified in scalar control and vector control categories.

In scalar control the fed-voltage changes proportionally with the frequency, but this type of control is used only when motor works in a low speed range [5].

Vector control, (usually implemented with Digital Signal Processors, DSP), is used when required specifications are more exigent (related to speed or position). There are two principal techniques:

I. Field oriented control (FOC). In this control, the stator current is controlled in bases of a synchronous $d-q$ frame [2], (Fig. 1 (a)).

II. Direct Torque Control (DTC). This control tries to achieve the desired torque by applying a vector voltage pattern table, (Fig. 1 (b) [6]).

Vector control usually uses an encoder to determine the rotor position. At present, research is focused on obtaining algorithms that estimate this rotor position without using encoders, (Sensorless Control [7], [8] and [9]).

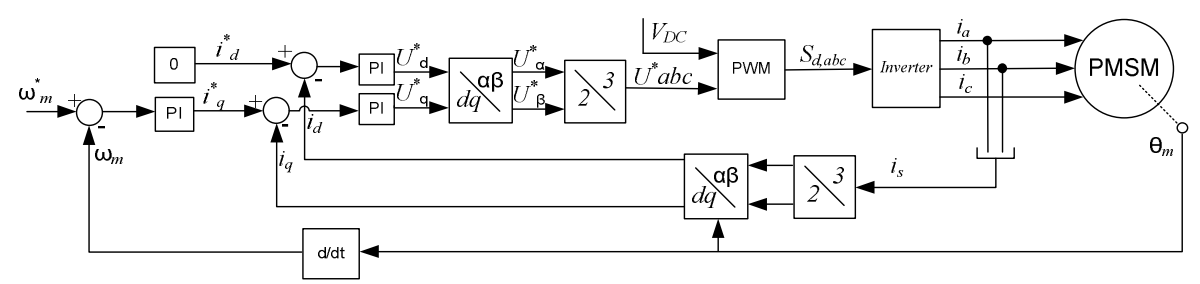

(a)

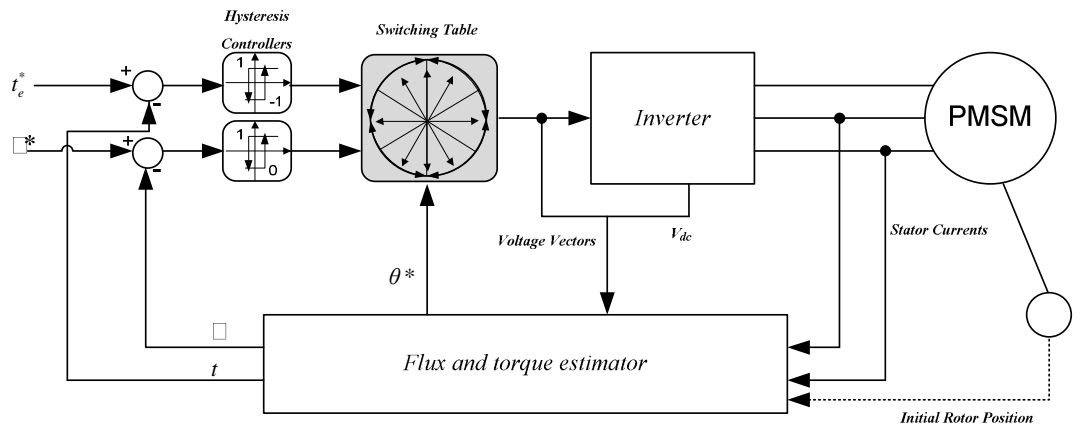

(b)

Fig. 1. Control System for PMSM: (a) FOC scheme, (b) DTC scheme 


\section{PMSM Performance}

In this section it will be analyzed the performance of the modeled PMSM. This performance evaluation will be carried out by analyzing torque-speed curves when a pre-established torque-speed pattern is applied to the motor.

In this work it is used an in-wheel PMSM model controlled by FOC and based in the concept of active flux [10],[11], defined as the flux that multiplies current $i_{q}$ in the expression (3). This model has been implemented using MATLAB/SIMULINK, (Fig. 2).

Two cases are studied to compare the influence of the PI coefficients of the angular speed regulator in the performance curves and also in the motor losses.

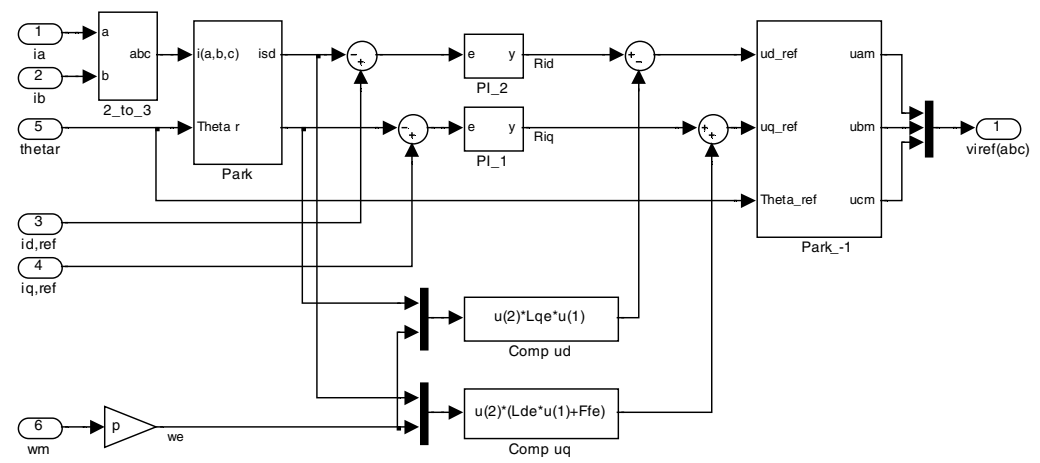

Fig. 2. Block diagram of the proposed control strategy for the PMSM in SIMULINK

The coefficients used for the PI speed controllers, which influence on the system will be studied by simulation, are listed in Table 2, while the coefficients used for the current controllers are listed in Table 3 (the same coefficients are used for both components $d$ and $q$ because the difference between $L_{s d}$ and $L_{s q}$ is negligible and these parameters are not under this paper scope).

The overall motor response, for cases A and B, is shown in Fig. 3. Detailed information of transient states, in a speed-torque plane, is represented in Fig. 4, where it can be observed how the motor reaches a final steady state from another steady state, after a change in speed or torque reference values takes place, and it could be observer if there are or not oscillations that will produce additional losses.

These graphs are employed to determine the energy used in the transient state when is produced a speed or torque variation, by using the integral expression (6).

Table 4 shows the energy needed for changing the motor steady state

$$
\Delta E=\int_{t_{0}}^{t_{1}}\left(t_{e}-t_{L}\right) \omega d t
$$

Table 2. Speed controller coefficients

\begin{tabular}{lll}
\hline Symbol & Case A & Case B \\
\hline$k_{p}$ & 5 & 5 \\
$k_{i}$ & 500 & 5000 \\
\hline
\end{tabular}

Table 3. Current controller coefficients

\begin{tabular}{lll}
\hline Symbol & Component $d$ & Component $q$ \\
\hline$k_{p}$ & 50 & 50 \\
$k_{i}$ & 4000 & 4000 \\
\hline
\end{tabular}


Table 4. Energy (J)

\begin{tabular}{lllc}
\hline State & Case A & Case B & Relative variation (\%) \\
\hline Transient 1 (0 to 0.085) & 197.4518 & 202.5904 & 2.5 \\
Transient 2 (0.5 to 0.525) & -31.3359 & -26.325 & 19.03 \\
Transient 3 (0.7 to 0.74) & 28,5789 & 29.0108 & 1.5 \\
Total Profile & 194,6948 & 205,2762 & 5.15 \\
\hline
\end{tabular}
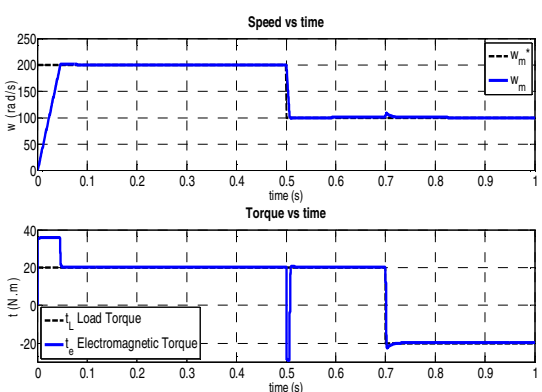

(a)
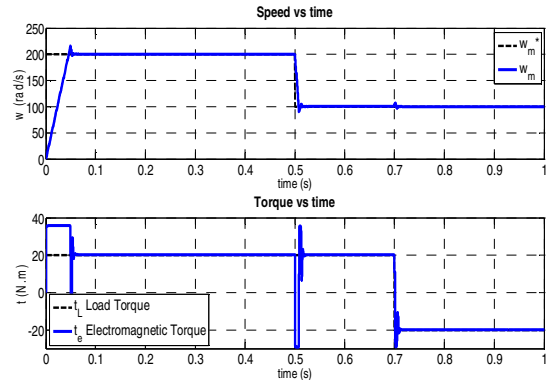

(b)

Fig. 3. Speed and torque standard curves (a) Case A, (b) Case B

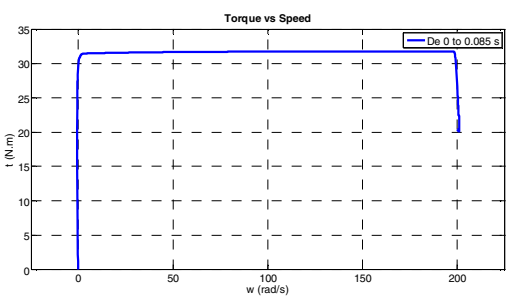

(a)

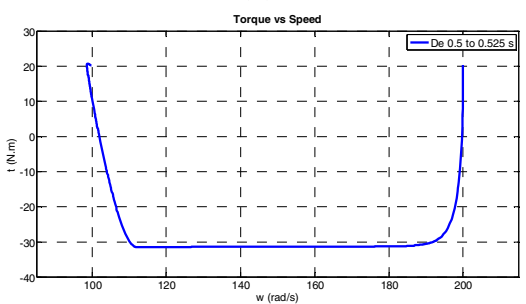

(c)

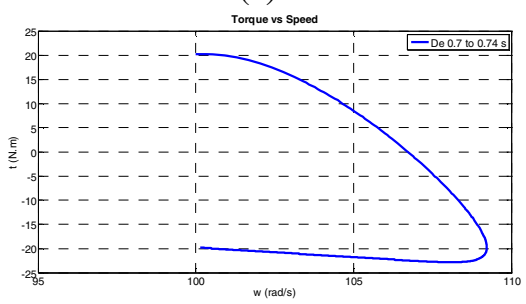

(e)

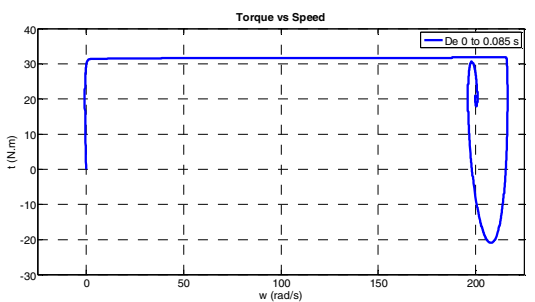

(b)

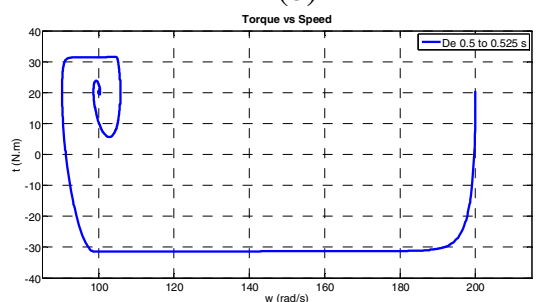

(d)

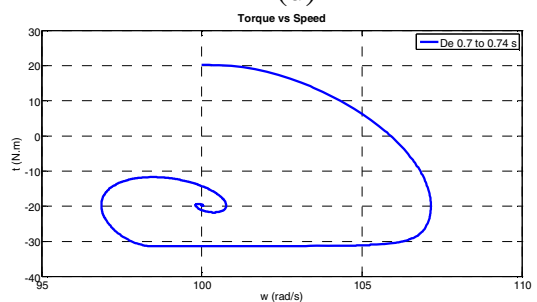

(f)

Fig. 4. Torque/Speed curves: Transient 1: (a) Case A, (b) Case B; Transient 2: (c) Case A, (d) Case B; Transient 3: (e) Case A, (f) Case B 
Three different transient intervals are established. The losses determined by (6) depend highly on the PI coefficients selected for the speed controller in the Transient 2 interval, (achieving a nearly $20 \%$ of variation), because the torque and speed oscillation causes additional friction and electrical (mainly due to Joule effect) losses. In the other transients this dependence it is not so high, and it is due to the nonlinearity of the motor and converter behavior.

\section{Switching Frequency Influence}

In this section, the losses that depend on the switching frequency, principally the converter losses, (conduction and switching), and the additional losses caused by the ripple current components produced in the motor windings will be analyzed.

For determining these losses a simulation test using PSIM has been done, (Fig. 5), because the inverter models calculate directly the conduction and switching losses. The PMSM has been modeled using the parameters of Table 1. The model has been simulated for different switching frequency values and for each simulation it has been wrote down the converter losses and then, the additional losses has been calculated. Every simulation is referred to a motor supplied by an ideal sinusoidal voltage that will produce sinusoidal currents calculating the losses by:

$$
P_{a d}=P_{c o n v}-P_{\text {sin }}=3 R\left(I_{r m s}^{2}-I_{1}^{2}\right) \text {. }
$$

The results of the simulation set are drawn in Fig. 6. As it was expected, the converter losses increase with the switching frequency and the additional electrical motor losses decrease with it. The curves cross near $400 \mathrm{~Hz}$, however, they show that the upslope of the losses of the inverter circuit does not grow in the same order of the decreasing load curve. Consequently, the frequency where the total losses are minimized in the simulation set is moved to frequencies higher than the corresponding to the point of intersection, (between the total losses of inverter circuit and load losses). If one considers optimizing the total losses, sum of converter and additional motor losses, the Fig. 6 shows that for this motor the optimum switching frequency is near $1 \mathrm{kHz}$ (1350 Hz).

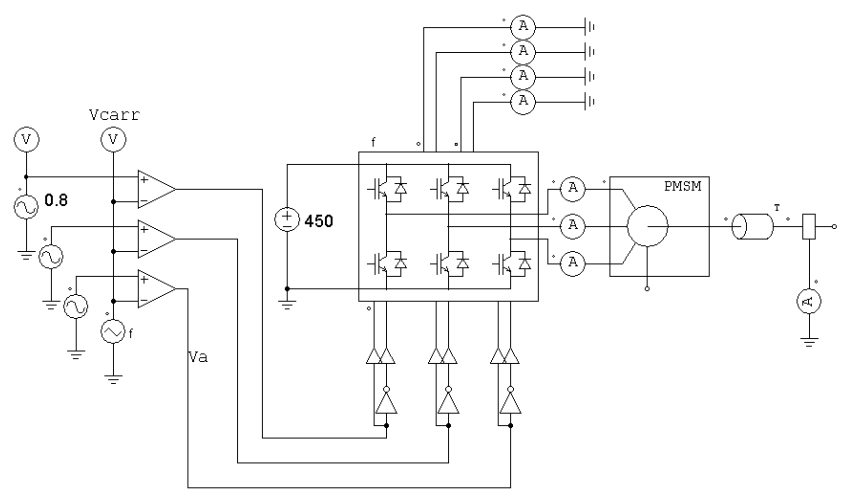

Fig. 5. Layout of test circuit in PSIM 


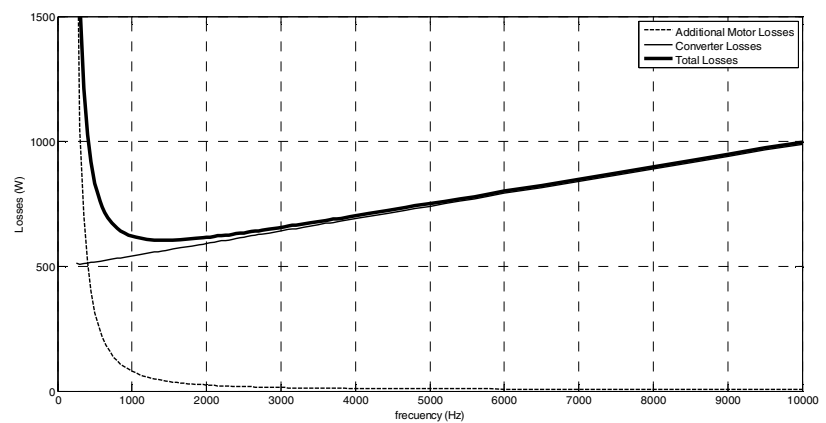

Fig. 6. Total loss of inverter circuit / motor

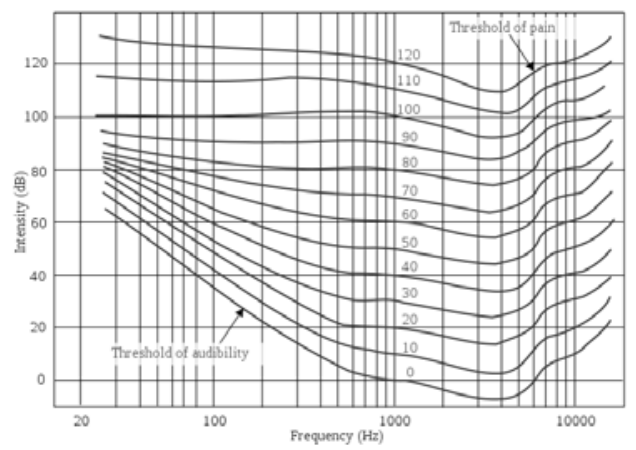

Fig. 7. Human Ear Frequency Range (Fletcher-Munson curves)

In the Fig. 7 the lower curve gives the faintest sounds that can be heard, and the upper curve gives the loudest sounds that can be heard without pain. Taken into account the results of the Fig. 6, a switching frequency of $1 \mathrm{kHz}$ assures that the application does not produce a high impact on human users due to reduction of engine noise of $10 \mathrm{~dB}$ [12], (especially in vehicle applications). The commercial servo amplifier used for the modeled motor recommends the operation with a switching frequency of $8 \mathrm{kHz}$ [13], which will produce, (in accordance with Fig. 6), a total losses increment of nearly $32 \%$ of the minimum (reached with $1.35 \mathrm{kHz}$ ).

\section{Conclusions}

In this paper it has been discussed some parameters that affect the efficiency of a PMSM, that could be used in electric vehicle applications and will affect its autonomy. It has been shown how the PI coefficient used in the speed controller affect the energy needed to do the transient states (acceleration and braking in vehicle application), being necessary an input energy up to $20 \%$ if these coefficients are not selected correctly. 
Also, it has been evaluated the total influence of the switching frequency, taken into consideration not only the converter losses, but also the additional losses that the switching components cause in the motor. For the commercial motor modeled in this paper, the switching frequency that minimized these total losses is near $1 \mathrm{kHz}$ that is a value much lower than the value usually recommended by manufacturers. By selecting this low switching frequency a total losses reduction of nearly $30 \%$ can be achieved.

Acknowledgments. This work has been developed under the project City-Elec supported by the Ministry of Science and Innovation from the Government of Spain.

\section{References}

1. Hill, R.J.: DC and AC Traction Motors. In: IEEE Conference, 9th Institution of Engineering and Technology Professional Development Course on Electric Traction Systems, pp. 33-52 (2007)

2. Chan, C.C., Chau, K.T.: An Overview of Power Electronics in Electric Vehicles. IEEE Transactions on Industrial Electronics 44, 3-13 (1997)

3. Pillay, P., Krishnan, R.: Control characteristics and Speed Controller Design for a High Performance Permanent Magnet Synchronous Motor Drive. IEEE Transactions on Power Electronics 5, 151-159 (1990)

4. Chunyuan, B., Shuangyan, R., Liangyu, M.: Study on Direct Torque Control of Super High-speed PMSM. In: IEEE International Conference on Automation and Logistics, pp. 2711-2715 (2007)

5. Szabo, C., Incze, I.I., Imecs, M.: Voltage-Hertz Control of the Synchronous Machine with Variable Excitation. In: IEEE International Conference on Automation, Quality and Testing, Robotics, vol. 1, pp. 298-303 (2006)

6. Foo, G.H.B., Rahman, M.F.: Direct Torque Control of an IPM-Synchronous Motor Drive at Very Low Speed Using a Sliding-Mode Stator Flux Observer. IEEE Transactions on Power Electronics 25, 933-942 (2010)

7. Kennel, R.: Encoderless Control of Synchronous Machines with Permanent Magnets Impact of Magnetic Design. In: IEEE International Conference on Optimization of Electrical and Electronic Equipment, pp. 19-24 (2010)

8. Ştirban, A., Boldea, I., Andreescu, G.-D., Iles, D., Blaabjerg, F.: Motion Sensorless Control of BLDC PM Motor with Offline FEM Info Assisted State Observer. In: IEEE International Conference on Optimization of Electrical and Electronic Equipment, pp. 321-328 (2010)

9. Iepure, L.I., Boldea, I., Andreescu, G.D., Iles, D., Blaabjerg, F.: Novel Motion Sensorless Control of Single Phase Brushless D.C. PM Motor Drive, with Experiments. In: IEEE Int. Conf. Optimization of Electrical \& Electronic Equipment, pp. 329-336 (2010)

10. Paicu, M.C., Boldea, I., Andreescu, G.D., Blaabjerg, F.: Very Low Speed Performance of Active Flux Based Sensorless Control: Interior Permanent Magnet Synchronous Motor Vector Control Versus Direct Torque and Flux Control. IET Electric Power Applications 3, 551-561 (2009)

11. Boldea, I., Paicu, M.C., Andreescu, G.-D.: Active Flux Concept for Motion Sensorless Unified AC Drives. IEEE Transactions on Power Electronics 23, 2612-2618 (2008)

12. Verheijen, E., Jabben, J.: Effect of Electric Cars on Traffic Noise and Safety. National Institute for Public Health and Environment of Netherlands (2010)

13. Mavilor Express Magazine (September 2003) 